\title{
Antiplasmodial profile of selected compounds from Malaria Box: in vitro evaluation, speed of action and drug combination studies
}

\author{
Guilherme Eduardo de Souza ${ }^{1}$ (B), Renata Vieira Bueno ${ }^{1}$ (), Juliana Oliveira de Souza ${ }^{1}$, \\ Camila Lima Zanini ${ }^{1} \mathbb{0}$, Fábio Cardoso Cruz $^{2} \mathbb{B}$, Glaucius Oliva ${ }^{1} \mathbb{0}$, Rafael Victório Carvalho Guido ${ }^{1 *}(\mathbb{0})$ \\ and Anna Caroline Campos Aguiar ${ }^{1 *}$ (1)
}

\begin{abstract}
Background: Artemisinin-based combination therapy (ACT) is used as the first-line treatment of uncomplicated malaria caused by the Plasmodium falciparum parasite and chloroquine-resistant Plasmodium vivax parasites. Evidence of resistance to ACT has been reported in Cambodia, and without new and effective anti-malarial agents, malaria burden and mortality will rise.

Methods: The used MolPrint 2D fingerprints and the Tanimoto similarity index were used to perform a structural similarity search within the Malaria Box collection to select diverse molecular scaffolds that are different from artesunate. Next, the inhibitory potency against the P. falciparum 3D7 strain (SYBR Green I inhibition assay) and the cytotoxicity against HepG2 cells (MTT and neutral red assays) were evaluated. Then, the speed of action, the combination profile of selected inhibitors with artesunate, and the P. berghei in vivo activity of the best compounds were assessed.

Results: A set of 11 structurally diverse compounds from the Malaria Box with a similarity threshold of less than 0.05 was selected and compared with artesunate. The in vitro inhibitory activity of each compound confirmed the reported potencies ( $\left(\mathrm{C}_{50}\right.$ values ranging from 0.005 to $\left.1 \mu \mathrm{M}\right)$. The cytotoxicity of each selected compound was evaluated and used to calculate the selectivity index (SI values ranging from 15.1 to 6100). Next, both the speed of action and the combination profile of each compound with artesunate was assessed. Acridine, thiazolopyrimidine, quinoxaline, benzimidazole, thiophene, benzodiazepine, isoxazole and pyrimidoindole derivatives showed fast in vitro inhibitory activity of parasite growth, whereas hydrazinobenzimidazole, indenopyridazinone and naphthalenone derivatives were slow-acting in vitro inhibitors. Combinatory profile evaluation indicated that thiazolopyrimidinone and benzodiazepine derivatives have an additive profile, suggesting that the combination of these inhibitors with artesunate is favourable for in vitro inhibitory activity. The remaining compounds showed an antagonistic combinatory profile with artesunate. The collected data indicated that the indenopyridazinone derivative, a bc $c_{1}$ complex inhibitor, had a similar association profile in combination with proguanil when compared to atovaquone combined with proguanil, thereby corroborating the correlation between the molecular target and the combination profile. Lastly, the in vivo activity of
\end{abstract}

\footnotetext{
*Correspondence: rvcguido@usp.br; carolcaguiar@yahoo.com.br 1 Sao Carlos Institute of Physics, University of Sao Paulo, Av. Joao Dagnone, 1100 Jardim Santa Angelina, São Carlos, SP 13563-120, Brazil

Full list of author information is available at the end of the article
}

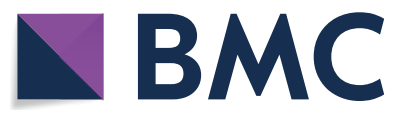

(c) The Author(s) 2019. This article is licensed under a Creative Commons Attribution 4.0 International License, which permits use, sharing, adaptation, distribution and reproduction in any medium or format, as long as you give appropriate credit to the original author(s) and the source, provide a link to the Creative Commons licence, and indicate if changes were made. The images or other third party material in this article are included in the article's Creative Commons licence, unless indicated otherwise in a credit line to the material. If material is not included in the article's Creative Commons licence and your intended use is not permitted by statutory regulation or exceeds the permitted use, you will need to obtain permission directly from the copyright holder. To view a copy of this licence, visit http://creativeco mmons.org/licenses/by/4.0/. The Creative Commons Public Domain Dedication waiver (http://creativecommons.org/publicdomain/ zero/1.0/) applies to the data made available in this article, unless otherwise stated in a credit line to the data. 
the thiazolopyrimidinone and benzodiazepine derivatives were assessed. Both compounds showed oral efficacy at $50 \mathrm{mg} / \mathrm{kg}$ in a mouse model of Plasmodium berghei malaria (64\% and 40\% reduction in parasitaemia on day 5 postinfection, respectively).

Conclusions: The findings in this paper shed light on the relationship among the speed of action, molecular target and combinatory profile and identified new hits with in vivo activity as candidates for anti-malarial combination therapy.

Keywords: Antimalarial, Drug resistance, Combination therapy, Drug development, Malaria Box

\section{Background}

Malaria is a tropical disease with the highest mortality rate in low-income countries. In 2017, 212 million new cases and 435,000 deaths were reported [1]. Plasmodium falciparum is responsible for the majority of malaria deaths globally and is the most prevalent species in sub-Saharan Africa [2].

Artemisinin-based combination therapy (ACT) is the first-line treatment for uncomplicated malaria caused by the $P$. falciparum parasite and chloroquine-resistant Plasmodium vivax parasites [3]. The combination of an artemisinin derivative with active compounds with different mechanisms of action improves the efficacy of the artemisinin analogue, reduces the treatment course, and decreases the resistance development potential [4]. However, since 2008, evidence of resistance to ACT has been reported in Cambodia, and patients with delayed parasite clearance under artemisinin treatment have been routinely identified [5-10]. Epidemiologic studies in southeast Asia and along India's borders have been monitoring the parasitic strains that are resistant to both artemisinin derivatives and partner drugs, such as mefloquine and piperaquine $[11,12]$. The spread of drug-resistant parasites can lead to an overall reduction in drug efficacy and treatment failure [7]. In the worstcase scenario, this spread could lead to an epidemic of drug-resistant malaria. Hence, malaria burden and mortality may significantly increase in the absence of new and effective drugs.

Medicines for Malaria Venture (MMV) is a leading product development partnership in the field of anti-malarial drug research and development. Aiming to catalyse a robust drug discovery process, MMV released in 2013 the Malaria Box, a collection of 400 free access compounds that show inhibitory activity against $P$. falciparum blood stages [13]. In this work, the antiplasmodial profile of 11 chemically diverse molecules selected from the Malaria Box was investigated. The compounds had their inhibitory activity against P. falciparum confirmed, their cytotoxicity evaluated and their speed-of-action and combination profile with artesunate assessed. Lastly, two promising compounds were selected for in vivo evaluation to complete the activity profile.

\section{Methods}

\section{Compound selection}

The 2D structures of artesunate and the 400 compounds from the Malaria Box were retrieved from the ChEMBL database (https://www.ebi.ac.uk/chembl), and their MolPrint 2D binary fingerprints were generated using the chemoinformatics software Canvas (Schrödinger, LLC, New York, NY) [14, 15]. The binary fingerprints of the 401 compounds were used to run a hierarchical clustering analysis using the Tanimoto similarity index and the average linkage method to calculate the distance between all inter-cluster pairs [14]. Eleven molecules from the Malaria Box, representing eight different clusters, were selected based on chemical diversity, physicochemical properties, and commercial availability from the same chemical supplier for inhibitory activity evaluation. In addition, the Molprint 2D fingerprints and Tanimoto similarity indices were used to compare artesunate and the selected compounds through a similarity matrix, with similarity indices varying from 0 to 1 [14]. The 11 molecules were purchased from the Ambinter, and stock solutions at a concentration of $20 \mathrm{mM}$ were prepared in 100\% DMSO before the in vitro assays.

\section{Maintenance of in vitro culture}

The $P$. falciparum 3D7 strain was kept in culture in a humidified incubator at $37{ }^{\circ} \mathrm{C}$ in RPMI-1640 medium with $25 \mathrm{mM} \mathrm{NaHCO}{ }_{3}, 25 \mathrm{mM}$ HEPES (pH 7.4), $11 \mathrm{mM}$ D-glucose, $3.67 \mathrm{mM}$ hypoxanthine and $25 \mu \mathrm{g} / \mathrm{mL}$ gentamicin, supplemented with $0.5 \%(\mathrm{~m} / \mathrm{v})$ AlbuMAX II. The culture medium was changed daily, and the parasitaemia was maintained below $10 \%$ with $2.5 \%$ haematocrit in human erythrocytes [16].

\section{SYBR Green I inhibition assay for the asexual stages of $P$. falciparum}

The parasites were synchronized through sterile 5\% $(\mathrm{m} / \mathrm{v})$ D-sorbitol treatment over $10 \mathrm{~min}$ at $37{ }^{\circ} \mathrm{C}$ for the enrichment of ring-stage parasites [17]. The cultures were pelleted by centrifugation at $600 \times g$ over $5 \mathrm{~min}$. The 
parasitaemia was determined by microscope analysis of thin blood smears stained with Giemsa $10 \%(\mathrm{v} / \mathrm{v})$ after methanol fixation. The initial parasitaemia was calculated from 1000 red blood cells (RBCs), and cultures were diluted to $0.5 \%$ parasitaemia and $2 \%$ haematocrit by adding the appropriate volumes of erythrocytes and medium. Parasite aliquots of $180 \mu \mathrm{L}$ were distributed into 96-well plates previously prepared with $20 \mu \mathrm{L}$ aliquots of a tenfold concentrated compound. Negative and positive control wells corresponding to non-parasitized erythrocytes and parasite cultures in the absence of compounds were set in parallel. The DMSO concentration was maintained below $0.05 \%(\mathrm{v} / \mathrm{v})$. The plates were incubated for $72 \mathrm{~h}$ at $37^{\circ} \mathrm{C}$ in a humidified incubator with a gas mixture of $90 \% \mathrm{~N}_{2}, 5 \% \mathrm{O}_{2}$ and $5 \% \mathrm{CO}_{2}$. After incubation, the culture medium was removed, and the cells were resuspended in $100 \mu \mathrm{L}$ PBS buffer $\left(116 \mathrm{mM} \mathrm{NaCl}, 10 \mathrm{mM} \mathrm{Na}_{2} \mathrm{HPO}_{4}\right.$, $3 \mathrm{mM} \mathrm{KH} \mathrm{PO}_{4}$ ) and lysed with $100 \mu \mathrm{L}$ lysis buffer $(20 \mathrm{mM}$ Tris base, $5 \mathrm{mM}$ EDTA, $0.0008 \%(\mathrm{v} / \mathrm{v})$ Triton $\mathrm{X}-100,0.008 \%(\mathrm{~m} / \mathrm{v})$ saponin, $\mathrm{pH} 8.0)$ containing $0.002 \%$ (v/v) SYBR Green I. Plates were incubated at room temperature for $30 \mathrm{~min}$, and the fluorescence corresponding to the parasitic density was determined using a SpectraMAX Gemini EM plate reader (Molecular Devices Corp., Sunnyvale, CA) (excitation at $485 \mathrm{~nm}$, emission at $535 \mathrm{~nm}$ ) [18]. The half maximal inhibitory concentration $\left(\mathrm{IC}_{50}^{\mathrm{Pf}}\right)$ was determined by non-linear regression analysis of the resulting concentration-response curve using the software Origin 2016 (OriginLab Corporation).

\section{Speed of action studies}

The speed of action of the anti-malarial candidates was verified by the incubation of the synchronized parasites at the ring stage in the presence of compounds at a concentration that was tenfold greater than the $\mathrm{IC}_{50}$ value. Parasites in thin blood smears were observed by microscopy after $0,8,16,24$ and 36 h of incubation [19].

\section{Prediction of drug absorption}

A multivariate approach developed by Egan et al. [20] was used to determine whether the investigated compounds could have membrane permeability issues. Calculated values of $\log$ P [21] and polar surface area (PSA) were used as independent parameters underlying the lipid-based diffusion to define value ranges that correlated with good absorption [20]. $\log$ P and PSA were plotted for each compound, and a $99 \%$ confidence ellipse outlined the area for well-absorbed compounds.

\section{Combination assays with artesunate}

Combinations of anti-malarial candidates with artesunate, an artemisinin derivative, were tested in fixed molar ratios based on the individual $\mathrm{IC}_{50}$ values that were previously determined by the SYBR Green I assay. Traditionally, a line (isobole) of additivity is used to distinguish between additive, synergic, and antagonistic interaction profiles. However, this additive profile is valid only for the interaction of compounds with a constant ratio of potencies, which is not the case for the anti-malarial compounds studied in this work (Additional file 1: Fig. S3). Thus, a systematic consideration of additivity ranges was included in the isobologram analysis, as previously described by Grabovsky and Tallarida [22]. Concentration-response curves of individual compounds were used in the calculation of each pair's additivity range (area within the upper and lower limits in Figs. 4 and 5). Fractional inhibitory concentration $\left(\mathrm{FIC}_{50}\right)$ pairs plotted as points inside the additivity range indicate the expected sum of each compound effect, while points above and below the range indicate antagonistic and synergic interactions, respectively. The selected inhibitors were combined with artesunate in the $\mathrm{IC}_{50}$ equivalent ratios of $1: 4$, 2:3, 1:1, 3:2 and 4:1 for the construction of the isobolograms [23].

\section{Hepatocarcinoma cell cultures and cytotoxicity evaluation} Hepatocarcinoma cells (HepG2) were cultivated in RPMI medium supplemented with $10 \%(\mathrm{v} / \mathrm{v})$ fetal bovine serum and $0.2 \%(\mathrm{v} / \mathrm{v})$ penicillin/streptomycin. The antibiotics were added to the medium to eliminate the potential interference of microbial contamination. Cells were cultivated at $37{ }^{\circ} \mathrm{C}$ and $5 \% \mathrm{CO}_{2}$; the supplemented medium was changed every 2 days.

For the experimental procedures, cells were trypsinized and transferred to a 96-well plate at 30,000 cells per well and incubated at $37{ }^{\circ} \mathrm{C}$ overnight for cell adhesion. Then, serial dilutions of the inhibitor candidates were added to the plate. Cells without any compounds were used as positive growth controls. The plate was incubated at $37{ }^{\circ} \mathrm{C}$ and $5 \% \mathrm{CO}_{2}$ for $72 \mathrm{~h}$. After incubation, the highest compound concentration to be considered (highest concentration without precipitation) was observed by microscopy. Cytotoxicity was evaluated by two different methods. The first is a colorimetric assay based on metabolic cell activity in the presence of 3-(4,5-dimethylthiazol-2-yl)-2,5-diphenyltetrazolium bromide (MTT) [24]. Briefly, mitochondrial enzymes can convert the MTT dye into the purple insoluble compound formazan. To each well, $20 \mu \mathrm{L}$ MTT at $5 \mathrm{mg} / \mathrm{mL}$ was added, followed by incubation at $37^{\circ} \mathrm{C}$ for 3 to $5 \mathrm{~h}$. After incubation, the supernatant was removed, and formazan crystals were solubilized in $100 \mu \mathrm{L}$ DMSO. The absorbance, which is proportional to the number of viable cells, was determined using a SpectraMAX Plus 384 plate reader (Molecular Devices Corp., Sunnyvale, CA) $(\lambda=570 \mathrm{~nm})$ [25]. The second method is based on 
the uptake of neutral red, a dye that is retained inside the lysosomes of viable cells. To each well, after removal of culture media, $200 \mu \mathrm{L}$ neutral red medium $40 \mu \mathrm{g} / \mathrm{mL}$ was added, followed by incubation at $37{ }^{\circ} \mathrm{C}$ for 3 to $5 \mathrm{~h}$. After incubation, supernatant was dispensed, and $200 \mu \mathrm{L}$ $0.5 \%(\mathrm{v} / \mathrm{v})$ formaldehyde in $1 \%(\mathrm{~m} / \mathrm{v}) \mathrm{CaCl}_{2}$ was added to remove excess of the dye for $5 \mathrm{~min}$. Supernatant was dispensed, and $100 \mu \mathrm{L}$ alcohol-acid solution (50\% (v/v) ethanol, $1 \%(\mathrm{v} / \mathrm{v})$ glacial acetic acid) was added, and the plate was stirred until a homogeneous solution was formed. The absorbance was determined using a SpectraMAX Plus 384 plate reader (Molecular Devices Corp., Sunnyvale, CA) $(\lambda=540 \mathrm{~nm})$ [26]. For both methods, the half maximal inhibitory concentration $\left(\mathrm{IC}_{50}^{\mathrm{HepG}}\right)$ was determined by non-linear regression analysis of the resulting concentration-response curve using the software Origin 2016 (OriginLab Corporation).

\section{In vivo assay against Plasmodium berghei}

A suppressive parasite growth test was performed in mice infected with $P$. berghei NK65 strain (originally received from the New York University Medical School), as described previously [27], with some modifications. Briefly, adult Swiss outbred mice ( $20 \pm 2 \mathrm{~g}$ weight) were intraperitoneally inoculated with $1 \times 10^{5}$ red blood cells infected with $P$. berghei. The infected mice were maintained together for at least $2 \mathrm{~h}$ and then randomized into groups of 5 animals per cage, which were subsequently administered $50 \mathrm{mg} / \mathrm{kg}$ of each compound diluted in $3 \%$ (v/v) DMSO by oral gavage daily for 3 days. Two control groups were used in parallel: one was treated with $C Q$ $(20 \mathrm{mg} / \mathrm{kg})$ and the other was treated with the vehicle. Blood smears from mouse tails were prepared on days 5 and 7 post-infection and then fixed with methanol, stained with Giemsa $10 \%(\mathrm{v} / \mathrm{v})$, and examined under the microscope. Parasitaemia was evaluated and the percent inhibition of parasite growth was calculated in relation to the untreated group (considered 100\% growth) using the following equation:

$$
[(\mathrm{C}-\mathrm{T} / \mathrm{C})] \times 100,
$$

where $C$ is the parasitemia in the control group and $T$ is the parasitaemia in the treated group. The use of laboratory animals was approved by the Ethics Committee for Animal Use of Universidade Federal do Estado de São Paulo, UNIFESP (CEUA N 6630080816).

\section{Results}

\section{Malaria Box compound selection}

The 400 compounds that comprise the Malaria Box were selected considering the chemical diversity, potency, and commercial availability of an initial set of compounds containing 19,873 unique hits [13]. Based on that, chemoinformatic approaches were used to select representative compounds from the Malaria Box that were as dissimilar as possible to artesunate. In order to do this, the Molprint 2D fingerprints and Tanimoto similarity indices were applied to construct a similarity matrix and compare artesunate with the Malaria Box compounds. The 400 compounds from the Malaria Box were grouped into 40 clusters based on their atomic connectivity and topological distances. The similarity indices varied from 0 (dissimilar scaffold) to 1 (identical scaffold). A similarity threshold of less than 0.05 was employed and 11 representative scaffolds were selected based on chemical diversity and commercial availability from the same supplier for inhibitory activity evaluation.

This set of 11 compounds contains compounds that belong to eight different clusters with diverse physicochemical properties (Additional file 1: Figs S1 and S2). The selected scaffolds are very diverse and include diazines, piperidines, piperazines, benzimidazoles, thiophene heterocycles, halogen substituted phenyl rings, and aliphatic functional groups, such as carboxamides and carboxylates (Table 1). The similarity matrix of the 11 representative compounds and artesunate according to the Tanimoto metric and MolPrint2D fingerprint is represented in Fig. 1. According to the similarity matrix, the selected compounds share a structural similarity of less than 3\% with artesunate. Among the selected dataset, compounds 5 (MMV020439) and 7 (MMV007574) are the most similar ( $38 \%$ similarity). Both compounds were grouped in cluster 23 because they share a thiophene carboxamide substituent (Additional file 1: Figs S1 and S2), whereas compounds 3 (MMV007224) and 6 (MMV665934) share 23\% similarity due to the presence of a 4-bromophenyl substituent. The similarity index amongst the remaining set of compounds is less than $20 \%$.

\section{Inhibitory activity and cytotoxicity evaluation of selected Malaria Box compounds}

The 11 selected compounds were purchased from Ambinter, a chemical compound supplier and confirmed the reported in vitro inhibitory activity against the intraerythrocytic form of $P$. falciparum (3D7 strain) (Table 1 and Additional file 1: Fig. S3). In general, there was a good agreement between the reported and evaluated potency values $\left(r^{2}=0.8\right)$ (Table 1 , Additional file 1: Fig. $\mathrm{S} 4)$. The measured $\mathrm{IC}_{50}$ values ranged from $0.0056 \mu \mathrm{M}$ $\left(\mathrm{pIC}_{50}=8.3\right)$ to $1.6 \mu \mathrm{M}\left(\mathrm{pIC}_{50}=5.8\right)$ and were distributed across the range of two orders of magnitude (Table 1 and Additional file 1: Fig. S4). Therefore, the set of selected scaffolds includes representative bioactive compounds of the Malaria Box. Compound 8, a naphthalen-1 $(2 \mathrm{H})$ one derivative, was the most potent inhibitor among the 
Table 1 Inhibitory activity against $P$. falciparum (reported and evaluated IC $C_{50}^{\mathrm{Pf}} 3 \mathrm{D} 7$ strain), hepatocarcinoma cells using MTT assay

\begin{tabular}{|c|c|c|c|c|c|c|c|c|}
\hline$\#$ & Code & Structure & $\begin{array}{l}\text { Reported } \\
I C_{50}^{P f}(\mu \mathrm{M})\end{array}$ & $\begin{array}{l}\mathrm{IC}_{50}^{\mathrm{Pf}}(\mu \mathrm{M}) \\
\text { Average } \\
\text { (confidence } \\
\text { interval-95\%) }\end{array}$ & $\begin{array}{l}\mathrm{IC}_{50}^{\text {HepG2, MTT }} \\
(\mu \mathrm{M}) \text { Average } \\
\text { (confidence } \\
\text { interval-95\%) }\end{array}$ & $\begin{array}{l}\mathrm{IC}_{50}^{\text {HepG2, NR }} \\
(\mu \mathrm{M}) \text { Average } \\
\text { (confidence } \\
\text { interval-95\%) }\end{array}$ & $\begin{array}{l}\mathrm{SI}^{\mathrm{MTT}} \text { Average } \\
\text { (confidence } \\
\text { interval- 95\%) }\end{array}$ & $\begin{array}{l}\mathrm{SI}^{\mathrm{NR}} \text { Average } \\
\text { (confidence } \\
\text { interval-95\%) }\end{array}$ \\
\hline 01 & MMV006172 & & 0.142 & $\begin{array}{l}0.074(0.072- \\
0.076)\end{array}$ & $3.21(3.18-3.24)$ & $3.34(3.28-3.40)$ & $43.4(42.6-44.2)$ & $45.1(44.6-45.6)$ \\
\hline 02 & MMV665971 & & 0.489 & $0.40(0.39-0.41)$ & $22(16-28)$ & $22(18-26)$ & $60(50-70)$ & $55(46-64)$ \\
\hline 03 & MMV007224 & & 1.06 & $0.34(0.29-0.39)$ & $5.1(4.5-5.7)$ & $>6.25$ & $15.1(14.6-15.6)$ & $>16$ \\
\hline 04 & MMV666607 & & 0.142 & $0.44(0.36-0.52)$ & $>6.25$ & $>6.25$ & $>12$ & $>12$ \\
\hline 05 & MMV020439 & & 0.512 & $0.25(0.16-0.34)$ & $90(80-100)$ & $>100$ & $340(280-400)$ & $>290$ \\
\hline 06 & MMV665934 & & 1.07 & $1.2(0.5-1.9)$ & $>12.5$ & $>12.5$ & $>6.6$ & $>6.6$ \\
\hline 07 & MMV007574 & & 0.826 & $1.0(0.8-1.2)$ & $>25$ & $>25$ & $>21$ & $>21$ \\
\hline 08 & MMV085203 & & 0.0053 & $\begin{array}{l}0.0055(0.005- \\
0.006)\end{array}$ & $>50$ & $33(28-38)$ & $>8300$ & $\begin{array}{l}6100(5800- \\
6400)\end{array}$ \\
\hline 09 & MMV085583 & & 0.237 & $0.17(0.14-0.20)$ & $>12.5$ & $>12.5$ & $>63$ & $>63$ \\
\hline 10 & MMV018984 & & 0.693 & $0.85(0.78-0.92)$ & nd & nd & nd & nd \\
\hline
\end{tabular}


Table 1 (continued)

\begin{tabular}{|c|c|c|c|c|c|c|c|}
\hline \# Code & Structure & $\begin{array}{l}\text { Reported } \\
I C_{50}^{\mathrm{Pf}}(\mu \mathrm{M})\end{array}$ & $\begin{array}{l}\text { IC } C_{50}^{\text {Pf }}(\mu \mathrm{M}) \\
\text { Average } \\
\text { (confidence } \\
\text { interval-95\%) }\end{array}$ & $\begin{array}{l}\text { IC HepG2, MTT } \\
\text { ( } \mu \mathrm{M}) \text { Average } \\
\text { (confidence } \\
\text { interval-95\%) }\end{array}$ & $\begin{array}{l}\text { IC } C_{50}^{\text {HepG2, NR }} \\
(\mu \mathrm{M}) \text { Average } \\
\text { (confidence } \\
\text { interval-95\%) }\end{array}$ & $\begin{array}{l}\mathrm{SI}^{\mathrm{MTT}} \text { Average } \\
\text { (confidence } \\
\text { interval- 95\%) }\end{array}$ & $\begin{array}{l}\mathrm{SI}^{\mathrm{NR}} \text { Average } \\
\text { (confidence } \\
\text { interval-95\%) }\end{array}$ \\
\hline $11 \quad$ MMV019871 & & 0.345 & $1.6(1.5-1.7)$ & $>50$ & $>50$ & $>29$ & $>29$ \\
\hline Artesunate & & 0.008 & $\begin{array}{l}0.017(0.016- \\
0.018)\end{array}$ & $110(80-140)$ & $110(80-140)$ & $\begin{array}{l}7000(6000- \\
8000)\end{array}$ & $\begin{array}{l}7000(6000- \\
8000)\end{array}$ \\
\hline $2+$ artesunate & & - & $\begin{array}{l}0.015(0.014- \\
0.016)\end{array}$ & $\begin{array}{l}15.70(15.64- \\
15.74)\end{array}$ & $13.0(12.3-13.7)$ & $\begin{array}{l}1030(940- \\
1120)\end{array}$ & $850(820-880)$ \\
\hline $9+$ artesunate & & - & $\begin{array}{l}0.013(0.011- \\
0.015)\end{array}$ & $>12.5$ & $>12.5$ & $>840$ & $>840$ \\
\hline
\end{tabular}

\begin{tabular}{|c|c|c|c|c|c|c|c|c|c|c|c|c|}
\hline 01 & 1.00 & & & & & & & & & & & \\
\hline 02 & 0.00 & 1.00 & & & & & & & & & & \\
\hline 03 & 0.17 & 0.00 & 1.00 & & & & & & & & & \\
\hline 04 & 0.07 & 0.00 & 0.13 & 1.00 & & & & & & & & \\
\hline 05 & 0.08 & 0.02 & 0.12 & 0.08 & 1.00 & & & & & & & \\
\hline 06 & 0.07 & 0.00 & 0.23 & 0.11 & 0.05 & 1.00 & & & & & & \\
\hline 07 & 0.06 & 0.02 & 0.07 & 0.03 & 0.38 & 0.03 & 1.00 & & & & & \\
\hline 08 & 0.06 & 0.07 & 0.07 & 0.06 & 0.05 & 0.06 & 0.06 & 1.00 & & & & \\
\hline 09 & 0.04 & 0.07 & 0.05 & 0.02 & 0.05 & 0.02 & 0.06 & 0.14 & 1.00 & & & \\
\hline 10 & 0.07 & 0.00 & 0.04 & 0.07 & 0.05 & 0.11 & 0.07 & 0.07 & 0.02 & 1.00 & & \\
\hline 11 & 0.09 & 0.00 & 0.03 & 0.03 & 0.02 & 0.00 & 0.00 & 0.00 & 0.00 & 0.00 & 1.00 & \\
\hline art & 0.00 & 0.00 & 0.00 & 0.00 & 0.00 & 0.00 & 0.03 & 0.00 & 0.00 & 0.00 & 0.00 & 1.00 \\
\hline & 01 & 02 & 03 & 04 & 05 & 06 & 07 & 08 & 09 & 10 & 11 & art \\
\hline
\end{tabular}

Fig. 1 Similarity matrix for the eleven compounds (1-11) selected from the Malaria Box and artesunate (art). The similarity indices vary from 0 (minimum) to 1 (maximum) and are coloured as shades of blue and red, respectively

evaluated compounds $\left(\mathrm{IC}_{50}^{\mathrm{Pf}}=0.0056 \mu \mathrm{M}\right)$, whereas compound 11, a pyrimido[5,4-b]indol-4-amine derivative, was the less potent inhibitor $\left(\mathrm{IC}_{50}^{\mathrm{Pf}}=1.6 \mu \mathrm{M}\right)$.

The cytotoxicity of the selected compounds was determined using a human hepatic cell line (HepG2) with the MTT assay [24] and the neutral red assay [26]. The selectivity index (SI) was assessed as the ratio between the inhibitory activity against the hepatocytes $\left(\mathrm{IC}_{50}^{\mathrm{HepG} 2}\right)$ and $P$. falciparum $\left(\mathrm{IC}_{50}^{\mathrm{Pf}}\right)$. Values of $\mathrm{SI}>10$ indicate a favourable safety window between the effective concentration against the parasite and the toxic concentration to the human cell. Data from MTT and neutral red assays showed no significative discrepancies. The compounds were moderately to highly selective, with SI values ranging from 15.1 to 6100 (Table 1). The $\mathrm{IC}_{50}^{\mathrm{HepG} 2}$ for compound $\mathbf{1 0}$ was not determined due to the low solubility in the assay conditions.

\section{Speed of action analysis}

To further investigate the antiplasmodial profile of the selected inhibitors, the speed of action was assessed against the asexual intraerythrocytic stages of $P$. falciparum. Over the incubation time of $36 \mathrm{~h}$, one complete maturation cycle of the parasite was observed 




(from ring to schizont stage) under the assay conditions (control row, Fig. 2). Compounds $\mathbf{1}$ and $\mathbf{2}$ induced pyknotic nuclei formation, the irreversible chromatin condensation of a necrotic or apoptotic cell, after $16 \mathrm{~h}$ of incubation. For compounds 3, 5, 7, 9, 10 and 11, the microscopic analysis of the parasite morphology indicated that the parasites exhibited punctual shapes after $16 \mathrm{~h}$, suggesting that the parasite development stalled in the ring stage up to $36 \mathrm{~h}$ of incubation. However, in the presence of $\mathbf{4}, \mathbf{6}$, and $\mathbf{8}$, young trophozoites were observed after $36 \mathrm{~h}$ of incubation. Thus, the findings indicate that compounds $1-3,5,7,9-11$ are fast-acting inhibitors, whereas compounds $\mathbf{4 , 6}$, and $\mathbf{8}$ are slowacting inhibitors of in vitro parasite growth.



Fig. 3 Plot of PSA vs. AlogP98 for anti-malarial compounds, calculated using BIOVIA Draw 18.1. The red ellipse represents the $99 \%$ confidence limit for drugs with good absorption [20]

Using drug absorption prediction analysis, seven compounds $(\mathbf{1}, \mathbf{4}-\mathbf{6}, \mathbf{8}, \mathbf{1 0}$, and 11) fell into the 99\% confidence ellipse for well-absorbed drugs (Fig. 3). Accordingly, the computational analysis suggested that these inhibitors have favourable permeability properties, thereby suggesting that permeability may not be an issue related to the observed speed of action for this set of inhibitors.

\section{Isobologram analysis}

Aiming to profiling the combinatorial potential of the selected Malaria Box set, the inhibitory effect of each compound's association with artesunate was assessed. First, the combination profile of the control compounds was evaluated as follows: atovaquone in combination with proguanil, a pair of standard anti-malarial drugs with known synergistic effect [28], and artesunate with itself, which by the definition of Loewe additivity demonstrates an additive effect [29]. The isobolograms for both controls, atovaquone + proguanil (Fig. 4a) and artesunate + artesunate (Fig. 4b) indicate synergic and additive profiles, respectively. Based on that, the combination profile of the 11 selected compounds was assessed in combination with artesunate (Fig. $4 \mathrm{c}-\mathrm{m}$ ). Table 2 shows the fraction of experimental data inside, above, and below the additive zone for each investigated compound. The isobolograms for each pair of inhibitors were classified as additive (inside the additive zone), antagonistic (above the additive zone) or synergic (below the additive zone).

The combinatory profile evaluation of the selected compounds indicated that compounds 2 (Fig. 4d) and 9 (Fig. 4k) have an additive profile (Table 2), suggesting 
(See figure on next page.)

Fig. 4 Isobolograms of controls and selected Malaria Box compounds. a Atovaquone with proguanil and $\mathbf{b}$ artesunate with itself were used as controls for synergic and additive profiles, respectively. $\mathbf{c}-\mathbf{m}$ Isobolograms of the 11 selected compounds in combination with artesunate. Black lines and grey areas indicate the arithmetic averages and standard deviations of the upper and lower limits of the additive area, respectively. Red dots indicate the experimental determination of the $\mathrm{FIC}_{50}$ pairs

that the combination of these inhibitors with artesunate is favourable for the in vitro inhibitory activity. In light of that, the inhibitory activity against $P$. falciparum, cytotoxicity and selectivity of the pairs in an equimolar proportion were determined for both additive combinations (Table 1). The remaining compounds $(\mathbf{1}, \mathbf{3 - 8}, \mathbf{1 0}$, and 11) showed an antagonistic combinatory profile with artesunate (Fig. 4 and Table 2). Compounds with similar atomic connectivity and topological distance distribution, as verified by the clusterization process, consistently showed the same combination profile. For instance, the two most similar compounds within the dataset (5 and 7) showed the same combination profile with artesunate (antagonistic).

Compound 6, an indeno[1,2-c]pyridazin-5-one derivative, has been identified as an inhibitor of the mitochondrial electron transport chain targeting the $\mathrm{bc}_{1}$ complex [30]. This inhibitory property motivated the investigation of combination profile of $\mathbf{6}$ as a replacement for atovaquone (a known $\mathrm{bc}_{1}$ complex inhibitor) in drug association [31]. Thus, the isobolograms of $\mathbf{6}+$ artesunate and $\mathbf{6}+$ proguanil was compared with the control isobolograms (atovaquone + artesunate and atovaquone + proguanil) (Fig. 5). The combination of $\mathbf{6}$ with artesunate is antagonistic, as observed by the association of the control atovaquone + artesunate (Fig. $5 \mathrm{a}$ and b). On the other hand, the isobologram of $\mathbf{6}$ with proguanil indicated a highly synergic combination profile, which is in good agreement with the profile observed for the control combination of atovaquone and proguanil (Fig. $5 \mathrm{c}$ and d), a recommended drug combination therapy for malaria.

\section{In vivo evaluation of selected Malaria Box compounds}

Motivated by the additive combination profile of compounds $\mathbf{2}$ and $\mathbf{9}$ with artesunate, their in vivo activity in $P$. berghei-infected mice was tested. Two groups of five infected mice were treated with $50 \mathrm{mg} / \mathrm{kg}$ of compounds 2 and 9 , respectively, via oral gavage for 3 consecutive days after infection. Parasitemia was evaluated on days 5 and 7 post-infection. The anti-malarial chloroquine was used as a positive control $(20 \mathrm{mg} / \mathrm{kg})$. Both compounds showed moderate in vivo activity, with compound 2 reducing parasitemia by $64 \%$ on day 5 and $33 \%$ on day 7 post-infection, whereas compound 9 reduced parasitemia by $40 \%$ on day 5 and $30 \%$ on day 7 post-infection (Fig. 6) (Table 3).

\section{Discussion}

Based on the efficacy of artemisinin-based combination therapy, a new anti-malarial drug will preferentially be administered in combination with artemisinin derivatives or some of the other drugs used against malaria [32]. The combination of anti-malarial drugs not only delays the emergence and spread of drug resistance but also has the potential to interrupt the transmission of $P$. falciparum [32]. Moreover, this strategy simultaneously decreases the necessary amount of each component and the chances of a toxic effect during therapy [33]. Therefore, the identification of suitable partners for combination therapy is crucial to reduce the potential of drug resistance.

The Malaria Box compounds have not yet been assessed for potential interactions with artemisinin derivatives, a gold-standard drug class in human malaria treatment [30]. In this work, a chemoinformatic approach was used to select a small but representative dataset of 11 compounds from the Malaria Box to investigate the antiplasmodial properties and identify favourable combination partners with artesunate. The similarity indices between the selected compounds and artesunate were as low as $3 \%$, indicating very dissimilar structural scaffolds. Next, the reported inhibitory activity of the selected set of inhibitors was confirmed and showed that the representative compounds have very low cytotoxicity against HepG2 cells ( $\mathrm{IC}_{50}^{\mathrm{HepG} 2}$ ranging from 3.21 to $>100 \mu \mathrm{M}$ ) and a high selectivity index (SI ranging from 15.1 to $>8300$ ). Then, both the speed of action and the association profile with artesunate was investigated.

Compounds 1-3, 5, 7, 9-11 showed fast inhibitory activity against in vitro parasite growth, whereas compounds 4, 6, and 8 showed slow inhibitory activity (Fig. 2). The set of selected compounds has a combination of favourable properties that contribute to high permeability through the membranes (Fig. 3). This finding suggests that the compounds' permeation properties are not related to the speed of action, indicating that the observed differences in the speed of action might be due to the inhibitors' mode of action [34]. In this context, the observed differences in the speed of action of artesunate, a fast anti-malarial agent, and compounds 4 (MMV666607), 6 (MMV665934) and 8 (MMV085203), which had slow antiplasmodial activity, suggest different mechanisms of inhibition against $P$. falciparum. 

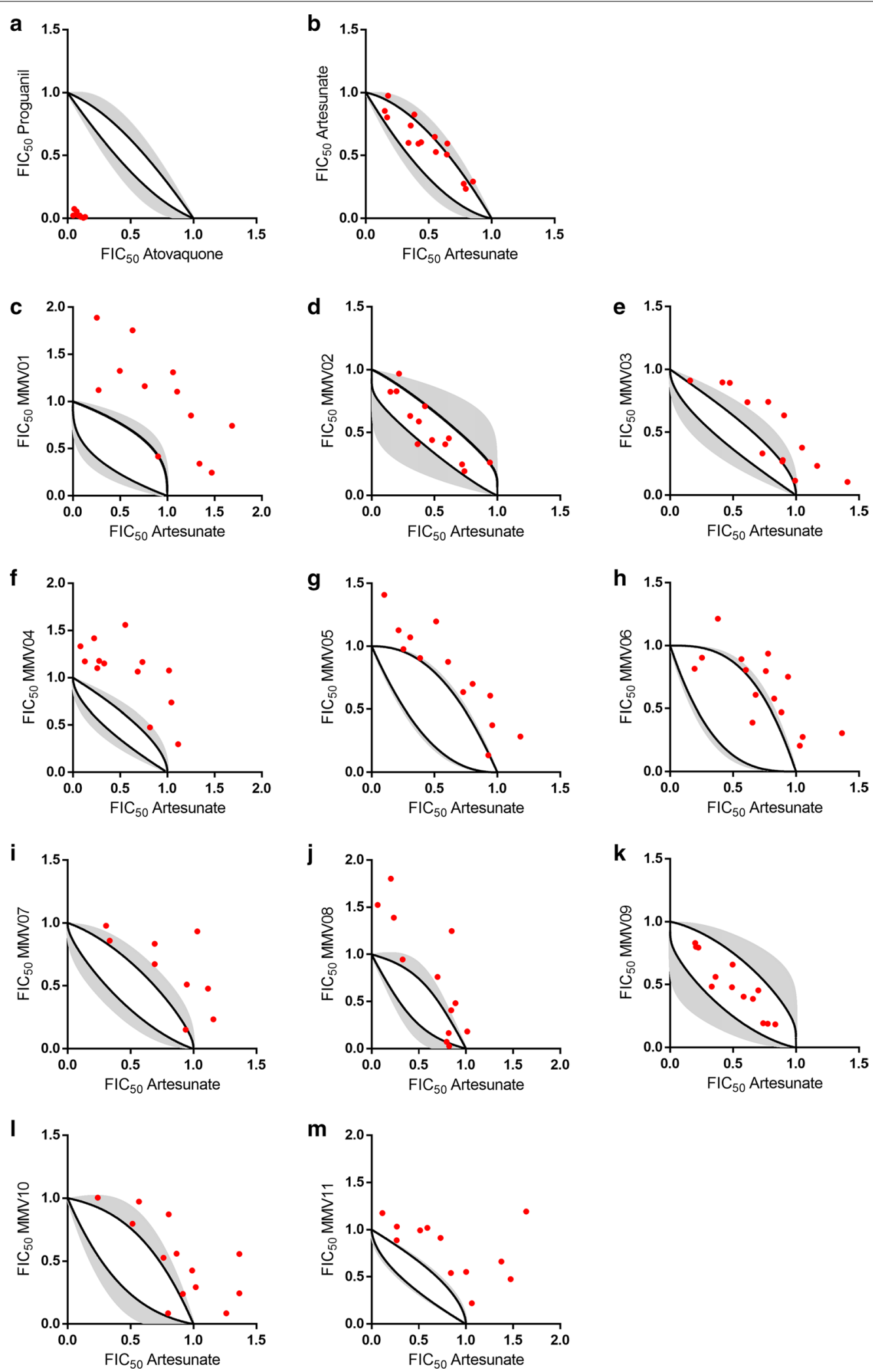
Table 2 Isobologram data and combination profiles of compounds 1-11 with artesunate. Numbers indicate how many FIC $_{50}$ pairs were located in each isobologram region

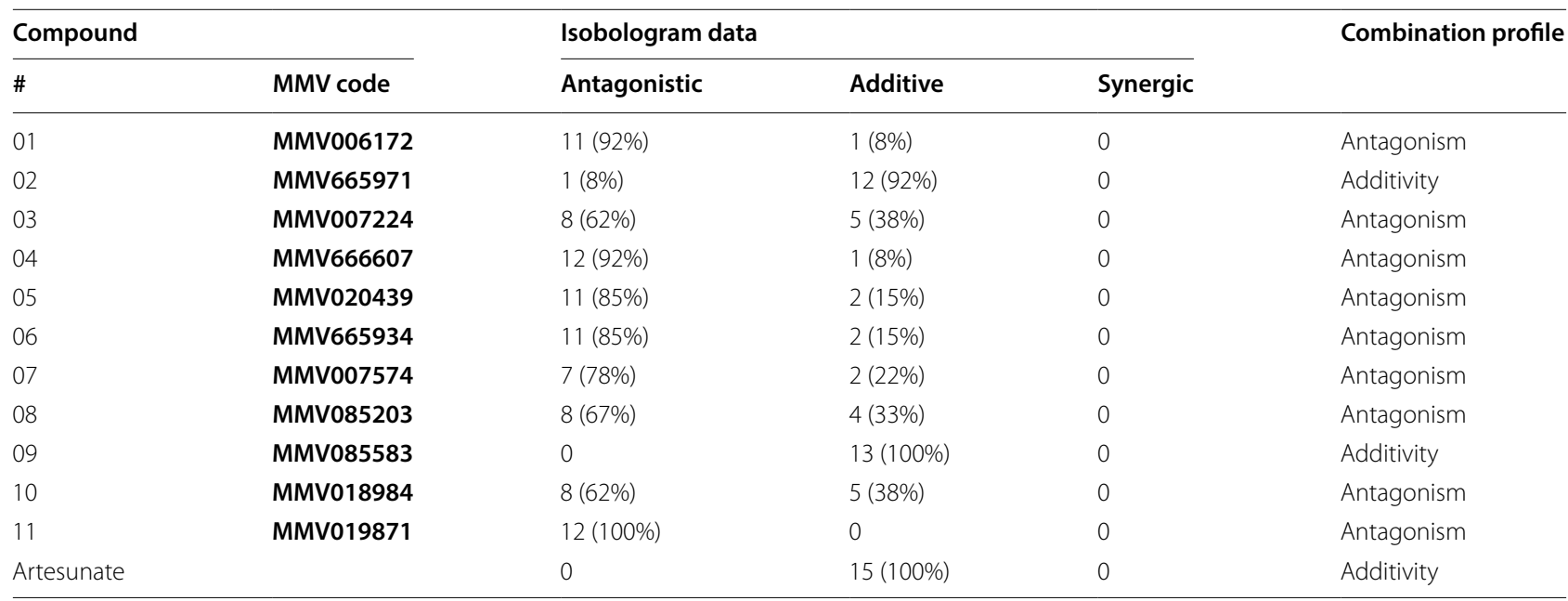
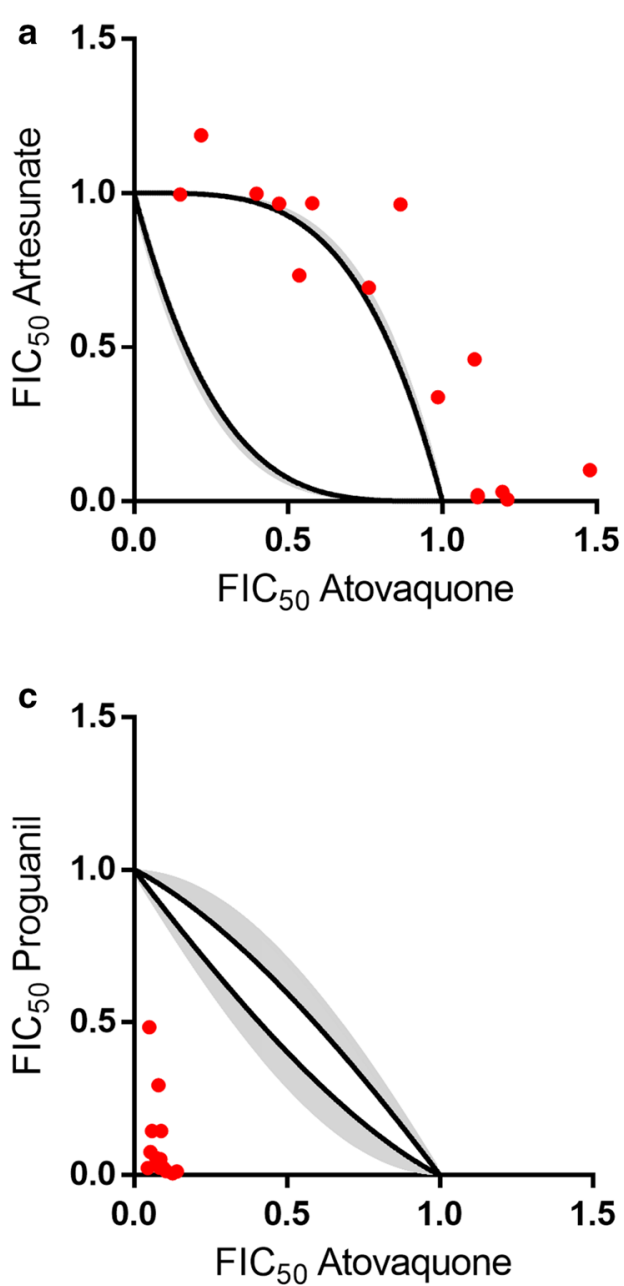
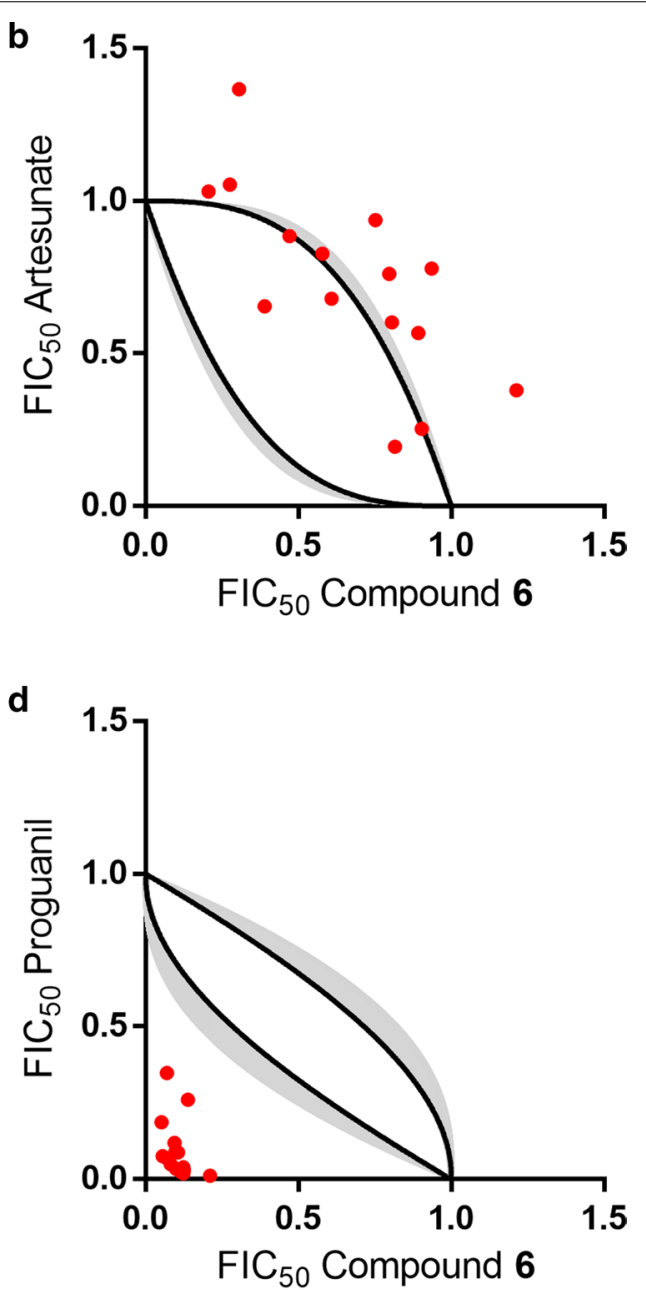

Fig. $\mathbf{5}$ Isobolograms of $\mathbf{a}$ artesunate + atovaquone (antagonistic), b artesunate $+\mathbf{6}$ as a surrogate for atovaquone (antagonistic), $\mathbf{c}$ proguanil + atovaquone (synergic), and (d) proguanil $+\mathbf{6}$ as a surrogate for atovaquone (synergic) 


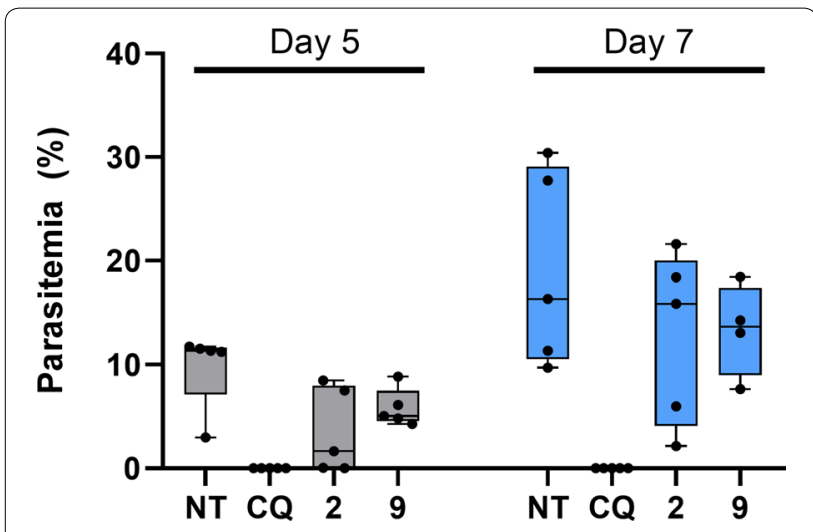

Fig. 6 Percentage parasitemia on days 5 and 7 after infection. Compounds $\mathbf{2}$ and $\mathbf{9}$ were administered at $50 \mathrm{mg} / \mathrm{kg}$ by oral gavage. Chloroquine (CQ) was used as a positive control at $20 \mathrm{mg} / \mathrm{kg}$, and data from untreated mice (NT) is presented for comparison

Table 3 Percentage of parasitaemia reduction after malaria treatment with 2 and 9

\begin{tabular}{lllr}
\hline Compound & Dose $\mathbf{( m g / k g )}$ & $\begin{array}{l}\text { \% of reduction, } \\
\text { days } \\
\text { after infection }\end{array}$ \\
\cline { 3 - 4 } & & $\mathbf{5}$ & $\mathbf{7}$ \\
\hline $\mathbf{2}$ & 50 & 64 & 33 \\
$\mathbf{9}$ & 50 & 40 & 30 \\
Chloroquine & 20 & 100 & 100 \\
\hline
\end{tabular}

Indeed, the slow inhibitory activity of compound $\mathbf{6}$ can be related to its molecular target (the $\mathrm{bc}_{1}$ complex) [30] because atovaquone, a $\mathrm{bc}_{1}$ complex inhibitor, is another slow anti-malarial agent [35]. The $\mathrm{bc}_{1}$ complex is a validated molecular target for new anti-malarial discovery and development $[31,36]$. The combination profile of $\mathbf{6}$ as a surrogate molecule for atovaquone in drug combination was investigated (Fig. 5). The collected data indicated that $\mathbf{6}$ in combination with proguanil had a similar association profile to atovaquone combined with proguanil, possibly due to $\mathbf{6}$ and atovaquone sharing the same molecular target.

Due to lower resistance development rates, different molecular targets are the primary selection factor for combination therapy [37]. It is important to emphasize that a different mode of action is only one of the selection criteria. Here, the combinatory profile evaluation of the selected compounds with artesunate indicated two different readouts: antagonistic and additive (Fig. 4). Compounds 1, 3-8, 10 and 11 showed antagonistic combinatory profiles with artesunate. Specifically, compounds 4 (MMV666607, a hydrazineyl- $1 H$-benzo $[d]$ imidazole derivative), 6 (MMV665934, an indeno[1,2-c] pyridazin-5-one derivative) and 8 (MMV085203, a 3-(piperidin-1-yl)naphthalen-1(2H)-one derivative) are slow-acting $P$. falciparum inhibitors, thereby suggesting a different mode of action related to artesunate (fast-acting inhibitor). However, compounds 4, 6, and 8 showed antagonistic combinatory profiles with artesunate. Hence, the findings underscore the need for a more detailed investigation in addition to the assessment of the mode of action for the identification of favourable combination partners. On the other hand, the isobologram analysis of two of the fast-acting inhibitors, 2 (MMV665971, a 2,3-dihydro-5H-thiazolo[3,2-a]pyrimidine-6-carboxylate derivative) and 9 (MMV085583, a 1-hydroxy-dibenzo[b,e] $[1,4]$ diazepine derivative), indicated an additive profile in combination with artesunate, suggesting that the association of these compounds with artesunate is favourable for the in vitro inhibitory growth of $P$. falciparum.

To better characterize the antimalarial potential of compounds $\mathbf{2}$ and $\mathbf{9}$, both inhibitors were selected for in vivo activity evaluation. Compounds $\mathbf{2}$ and $\mathbf{9}$ showed oral efficacy at $50 \mathrm{mg} / \mathrm{kg}$ in a mouse model of $P$. berghei malaria (64\% and 40\% reduction in parasitaemia on day 5 post-infection, respectively). The modest in vivo activity might be related to pharmacokinetics properties of the inhibitors. Previous pharmacokinetics studies revealed that compound 2 has poor oral bioavailability and high plasma protein binding (>99\%). Compound 9 showed a similar profile, but higher blood maximum concentrations [30]. Therefore, the improvement of the drug-like properties of $\mathbf{2}$ and $\mathbf{9}$ will enable the discovery of new promising ACT partners.

\section{Conclusions}

In this work, a similarity analysis to select a set of 11 representative compounds from the Malaria Box was carried out. Next, the reported inhibitory activity of the Malaria Box compounds was confirmed and the selected compounds were shown to have very low cytotoxicity against HepG2 cells and a high selectivity index. Then, both the speed of action and the association profile of artesunate with the 11 selected compounds were investigated. Compounds 1-3, 5, 7, 9-11 showed fast inhibitory activity of in vitro parasite growth, whereas compounds 4, 6 and 8 were slow-acting in vitro inhibitors, in contrast to artesunate, a fast in vitro inhibitor [34]. Compound 6 (MMV665934), a bc ${ }_{1}$ complex inhibitor, exhibited antagonistic and synergic combination profiles when used in association with artesunate and proguanil, respectively. These findings are in good agreement with the combination profiles of atovaquone with the gold-standard anti-malarial drugs and could 
be explained by 6 and atovaquone sharing the same molecular target. Compounds 2 (MMV665971) and 9 (MMV085583) did not interfere with the high potency of artesunate and positively contributed to the inhibitory activities in the combination assays, thereby indicating favourable combination potential with artesunate. Both compounds showed promising in vivo activity potential. The findings shed light upon the relationships between the speed of action, molecular targets and combinatory profiles, and identified new hits as candidates for anti-malarial combination therapy.

\section{Supplementary information}

Supplementary information accompanies this paper at https://doi. org/10.1186/s12936-019-3069-3.

Additional file 1: Fig. S1. Fragments of the dendrogram originated from the hierarchical clustering of 400 compounds from the Malaria Box, artesunate and atovaquone. Clusters 2, 16, 20, 23 and 25 are represented with the 2D structures from which they originated. Fig. S2. Fragments of the dendrogram originated from the hierarchical clustering of 400 compounds from Malaria Box, artesunate and atovaquone. Clusters 26, $27,29,32,35$ and 36 are represented with the 2D structures from which they originated. Fig. S3. Concentration-response curves of the selected compounds from the Malaria Box against P. falciparum (3D7). Curves in black and red refer to, respectively, the first and second experiment performed for the evaluation of the $I_{50}$ values. Fig. S4. Evaluated versus reported $\mathrm{plC}_{50}$ values

\section{Abbreviations}

$\mathrm{ACT}$ : artemisinin-based combination therapy; $I \mathrm{C}_{50}$ : half maximal inhibitory concentration; $\mathrm{FIC}_{50}$ : fractional half maximal inhibitory concentration; MMV: Medicines for Malaria Venture; MTT: 3-(4,5-dimethylthiazol-2-yl)-2,5-diphenyltetrazolium bromide; PSA: polar surface area; SI: selectivity index.

\section{Acknowledgements}

The authors are grateful to the Malaria Research and Reference Reagent Resource Center (MR4) for the donation of the Plasmodium falciparum strain used in this work and to the University of São Paulo for providing the equipment and facilities necessary for this work.

\section{Author contributions}

ACCA and RVCG conceived the study. GES, JOS, CLZ, and ACCA collected and analysed the in vitro data. GES, RVB, and RVCG performed the molecular modelling studies and analysed the computational data. GES, RVB, GO, RVCG, and ACCA analysed the data, contributed ideas, and wrote the manuscript. All authors reviewed the manuscript. All authors read and approved the final manuscript.

\section{Funding}

We thank São Paulo Research Foundation (FAPESP, CEPID grant 2013/076003, 2016/09772-4 to GES and 2015/18192-9 to ACCA), Conselho Nacional de Desenvolvimento Científico e Tecnológico (CNPq, grant 405330/2016-2 to RVCG, 130582/2016-6 to GES), CAPES (Coordenação de Aperfeiçoamento de Pessoal de Nível Superior-Brazil) Finance Code 001 and Serrapilheira Institute (grant Serra-1708-16250 to RVCG) for funding the research and fellowships.

\section{Availability of data and materials}

The datasets analysed during the current study are available from the corresponding author on reasonable request.

Ethics approval and consent to participate Not applicable.
Consent for publication

Not applicable.

\section{Competing interests}

The authors declare that they have no competing interests.

\section{Author details}

1 Sao Carlos Institute of Physics, University of Sao Paulo, Av. Joao Dagnone, 1100 Jardim Santa Angelina, São Carlos, SP 13563-120, Brazil. ${ }^{2}$ Department of Pharmacology, Federal University of São Paulo, Rua Botucatu 862, São Paulo, SP 04023-062, Brazil.

Received: 18 June 2019 Accepted: 10 December 2019

Published online: 30 December 2019

\section{References}

1. WHO. Malaria. Geneva, World Health Organization, 2018. https://www. who.int/news-room/fact-sheets/detail/malaria. Accessed 14 Feb 2019.

2. WHO. Malaria. World Health Organization Africa, 2019. https://www.afro. who.int/health-topics/malaria. Accessed 2 Nov 2019.

3. WHO. Overview of malaria treatment. Geneva, World Health Organization, 2018. https://www.who.int/malaria/areas/treatment/overview/en/. Accessed 10 Jan 2019.

4. Bosman A, Mendis KN. A major transition in malaria treatment: the adoption and deployment of artemisinin-based combination therapies. Am J Trop Med Hyg. 2007;77(Suppl 6):193-7.

5. Noedl H, Se Y, Schaecher K, Smith BL, Socheat D, Fukuda MM. Evidence of artemisinin-resistant malaria in Western Cambodia. N Engl J Med. 2008:359:2619-20.

6. Dondorp AM, Nosten F, Yi P, Das D, Phyo AP, Tarning J, et al. Artemisinin resistance in Plasmodium falciparum malaria. N Engl J Med. 2009;361:455-67.

7. Phyo AP, Nkhoma S, Stepniewska K, Ashley EA, Nair S, McGready R, et al. Emergence of artemisinin-resistant malaria on the western border of Thailand: a longitudinal study. Lancet. 2012;379:1960-6.

8. Herlekar I. The resistance gene in malaria parasite identified. Curr Sci. 2014;106:345.

9. Miotto O, Amato R, Ashley EA, Maclnnis B, Almagro-Garcia J, Amaratunga $C$, et al. Genetic architecture of artemisinin-resistant Plasmodium falciparum. Nat Genet. 2015;47:226-34.

10. Straimer J, Gnädig NF, Witkowski B, Amaratunga C, Duru V, Ramadani AP, et al. K13-propeller mutations confer artemisinin resistance in Plasmodium falciparum clinical isolates. Science. 2015;347:428-31.

11. Tun KM, Imwong M, Lwin KM, Win AA, Hlaing TM, Hlaing T, et al. Spread of artemisinin-resistant Plasmodium falciparum in Myanmar: a cross-sectional survey of the K13 molecular marker. Lancet Infect Dis. 2015;15:415-21.

12. Yeka A, Lameyre V, Afizi K, Fredrick M, Lukwago R, Kamya MR, et al. Efficacy and safety of fixed-dose artesunate-amodiaquine vs. artemetherlumefantrine for repeated treatment of uncomplicated malaria in Ugandan children. PLOS ONE. 2014;9:e113311.

13. Spangenberg T, Burrows JN, Kowalczyk P, McDonald S, Wells TNC, Willis P. The open access Malaria Box: a drug discovery catalyst for neglected diseases. PLoS ONE. 2013;8:e62906.

14. Duan J, Dixon SL, Lowrie JF, Sherman W. Analysis and comparison of 2D fingerprints: insights into database screening performance using eight fingerprint methods. J Mol Graph Model. 2010;29:157-70.

15. Sastry M, Lowrie JF, Dixon SL, Sherman W. Large-scale systematic analysis of 2D fingerprint methods and parameters to improve virtual screening enrichments. J Chem Inf Model. 2010:50:771-84.

16. Trager $W$, Jensen JB. Human malaria parasites in continuous culture. Science. 1976;193:673-5.

17. Lambros C, Vanderberg JP. Synchronization of Plasmodium falciparum erythrocytic stages in culture. J Parasitol. 1979;65:418-20.

18. Vossen MG, Pferschy S, Chiba P, Noedl H. The SYBR Green I malaria drug sensitivity assay: performance in low parasitemia samples. Am J Trop Med Hyg. 2010;82:398-401. 
19. Terkuile F, White NJ, Holloway P, Pasvol G, Krishna S. Plasmodium falciparum: in vitro studies of the pharmacodynamic properties of drugs used for the treatment of severe malaria. Exp Parasitol. 1993;76:85-95.

20. Egan WJ, Merz KM, Baldwin JJ. Prediction of drug absorption using multivariate statistics. J Med Chem. 2000;43:3867-77.

21. Ghose AK, Viswanadhan VN, Wendoloski JJ. Prediction of hydrophobic (lipophilic) properties of small organic molecules using fragmental methods: an analysis of ALOGP and CLOGP methods. J Phys Chem A. 1998;102:3762-72.

22. Grabovsky Y, Tallarida RJ. Isobolographic analysis for combinations of a full and partial agonist: curved isoboles. J Pharmacol Exp Ther. 2004;310:981-6.

23. Loewe $\mathrm{S}$. The problem of synergism and antagonism of combined drugs. Arzneimittelforschung. 1953;3:285-90.

24. Mosmann T. Rapid colorimetric assay for cellular growth and survival: application to proliferation and cytotoxicity assays. J Immunol Methods. 1983;65:55-63.

25. de Madureira MD, Martins AP, Gomes M, Paiva J, da Cunha AP, do Rosário V. Antimalarial activity of medicinal plants used in traditional medicine in S. Tomé and Príncipe islands. J Ethnopharmacol. 2002;81:23-9.

26. Repetto G, del Peso A, Zurita JL. Neutral red uptake assay for the estimation of cell viability/cytotoxicity. Nat Protoc. 2008;3:1125-31.

27. Peters W. Drug resistance in Plasmodium berghei Vincke and Lips, 1948.III. Multiple drug resistance. Exp Parasitol. 1965:17:97-102.

28. Canfield CJ, Pudney M, Gutteridge WE. Interactions of atovaquone with other antimalarial drugs against Plasmodium falciparum in vitro. Exp Parasitol. 1995;80:373-81.

29. Loewe S, Käer E, Muischnek H. Über Kombinationswirkungen. Naunyn Schmiedebergs Arch Exp Pathol Pharmakol. 1927;120:25-40.
30. Van Voorhis WC, Adams JH, Adelfio R, Ahyong V, Akabas MH, Alano P, et al. Open source drug discovery with the Malaria Box compound collection for neglected diseases and beyond. PLoS Pathog. 2016;12:1-23.

31. Srivastava IK, Rottenberg H, Vaidya AB. Atovaquone, a broad spectrum antiparasitic drug, collapses mitochondrial membrane potential in a malarial parasite. J Biol Chem. 1997;272:3961-6.

32. Nosten F, Brasseur P. Combination therapy for malaria. Drugs. 2002;62:1315-29.

33. Xiong G, Doraiswamy PM. Combination drug therapy for Alzheimer's disease: what is evidence-based, and what is not? Geriatrics. 2005;60:22-6.

34. Sanz LM, Crespo B, De-Cózar C, Ding XC, Llergo JL, Burrows JN, et al. P. falciparum in vitro killing rates allow to discriminate between different antimalarial mode-of-action. PLoS ONE. 2012;7:e30949.

35. Biagini GA, Fisher N, Shone AE, Mubaraki MA, Srivastava A, Hill A, et al. Generation of quinolone antimalarials targeting the Plasmodium falciparum mitochondrial respiratory chain for the treatment and prophylaxis of malaria. Proc Natl Acad Sci USA. 2012;109:8298-303.

36. Aguiar AC, de Sousa LRF, Garcia CRS, Oliva G, Guido RVC. New molecular targets and strategies for antimalarial discovery. Curr Med Chem. 2017. https://doi.org/10.2174/0929867324666170830103003.

37. Eastman RT, Fidock DA. Artemisinin-based combination therapies: a vital tool in efforts to eliminate malaria. Nat Rev Microbiol. 2009;7:864-74.

\section{Publisher's Note}

Springer Nature remains neutral with regard to jurisdictional claims in published maps and institutional affiliations.
Ready to submit your research? Choose BMC and benefit from:

- fast, convenient online submission

- thorough peer review by experienced researchers in your field

- rapid publication on acceptance

- support for research data, including large and complex data types

- gold Open Access which fosters wider collaboration and increased citations

- maximum visibility for your research: over 100M website views per year

At BMC, research is always in progress.

Learn more biomedcentral.com/submissions 